\title{
Upper Zone of Growth Plate and Cartilage Matrix (UCMA) Levels in Patients with Chronic Kidney Disease
}

\author{
Hamza Malik Okuyan ${ }^{1 *}$ \\ https://orcid.org/0000-0001-7616-3330 \\ Oğuzhan Özcan ${ }^{2}$ \\ https://orcid.org/0000-0001-7486-503X

\section{Serdar Doğan²} \\ https://orcid.org/0000-0001-6854-2197
}

Abdullah Arpacı ${ }^{2}$

https://orcid.org/0000-0002-6077-8258

\section{Faruk Hilmi Turgut ${ }^{3}$ \\ https://orcid.org/0000-0003-1910-7433}

'Sakarya University of Applied Sciences, Faculty of Health Sciences, Department of Physiotherapy and Rehabilitation, Sakarya, Turkey; ${ }^{2}$ Hatay Mustafa Kemal University, Faculty of Medicine, Department of Biochemistry, Hatay, Turkey; ${ }^{3}$ Hatay Mustafa Kemal University, Faculty of Medicine, Department of Nephrology, Hatay, Turkey.

Received: 2019.09.23; Accepted: 2020.03.21.

*Correspondence: hmokuyan@subu.edu.tr; Tel.: +90 26461600 54; (H.M.O.)

\section{HIGHLIGHTS}

- The relationship between UCMA and renal function were shown for the first time

- UCMA levels are associated with Ca metabolism in CKD

- Similar expression levels of UCMA with mineralization markers involved in CKD.

Abstract: Chronic kidney disease (CKD) is an important health problem across the world affecting the adult population with an enormous social and economic burden. Calcium regulation is also affected in patients with $\mathrm{CKD}$, and related to several disorders including vascular calcifications, mineral bone disorders, and cardiovascular diseases (CVD). Upper zone of growth plate and cartilage matrix (UCMA) is vitamin Kdependent protein (VKDP) and acts as a calcification inhibitor in the cardiovascular system. The molecular mechanism of UCMA action remains unclear in CKD. In the current study, we aimed to investigate serum total UCMA levels and its association with calcium metabolism parameters in CKD patients including hemodialysis (HD) patients. Thirty-seven patients with CKD stage 3-5, $41 \mathrm{HD}$ patients, and 34 healthy individuals were enrolled in this cross-sectional study. Serum UCMA and calcification related protein levels (Matrix Gla Protein (MGP), Osteocalcin (OC), and Fetuin-A) were analyzed with enzyme-linked immunosorbent assay (ELISA). Calcium mineral disorder parameters (Serum $\mathrm{Ca}, \mathrm{P}, \mathrm{iPTH}$ ) were quantified with routine techniques. We, for the first time, report the potential biomarker role of UCMA in CKD including HD. Serum total UCMA levels were significantly higher in patients with CKD including HD patients than the healthy controls. Also, serum UCMA levels showed negative correlations with serum calcium, and eGFR, while showed positive relationships with P, iPTH, MGP, OC. Increased total UCMA levels may have a role in the Ca metabolism disorder and related to the pathogenesis of Vascular Calcification in patients with CKD. 
Keywords: chronic kidney disease; hemodialysis; UCMA; GRP; MGP; OC.

\section{INTRODUCTION}

Chronic kidney disease (CKD) is an important health problem across the world, affecting almost 10 to 15 percent of the adult population [1]. A disease burden study estimated that approximately 5 - 10 million people die annually because of kidney diseases, and the treatment of kidney diseases in developed countries imposes a considerable burden on the health care system [2]. CKD affects many organ systems, including the endocrine, nervous, and cardiovascular system and has detrimental effects on the clinical outcomes [3]. Calcium regulation is also affected in patients with CKD, which is related to mineral bone disorders, and cardiovascular diseases (CVD), and these disorders in patients with CKD have a significant impact on morbidity and mortality [4]. Parathyroid hormone (PTH), Fibroblast growth factor-23 (FGF23), 1,25-dihydroxy vitamin $D(1,25 \mathrm{D})$, Calcium $(\mathrm{Ca})$, and Phosphorus $(\mathrm{P})$ are among the most important factors that play a role in abnormal $\mathrm{Ca}$ metabolism [4]. Regulation and balance of $\mathrm{Ca}$ are very important because both negative and positive $\mathrm{Ca}$ balance have deleterious effects for patients with CKD [5]. Negative Ca balance lead to bone mineral loss, osteoporosis, and bone fracture risk, while positive Ca balance supports vascular or soft tissue calcification, resulting in increased morbidity and mortality [5]. However, the molecular mechanism underlying calcium imbalance, which is related to bone mineral disorders and vascular calcifications (VC) is not completely understood and current treatment is insufficient [5]. It appears to be clinically good to try to maintain neutral calcium levels due to the detrimental effects of calcium imbalance in CKD. Therefore, further studies are needed to identify new molecules predicting calcium balance in patients with CKD.

UCMA (upper zone of growth plate and cartilage matrix), (also known Gla rich Protein, GRP), is one of the newest members of the vitamin K-dependent protein (VKDP) family and was first discovered in 2008 by Viegas and coauthors [6]. More recently, UCMA has been reported to function as both a calcification inhibitor in the cardiovascular system and an anti-inflammatory agent in the immune cells [7-9]. Accumulation and expression of UCMA have been shown in human and rat soft tissues including skin and vascular system [10]. UCMA is a protein that has a high binding affinity to calcium mineral, indicating that regulatory role in calcium availability in the extracellular matrix $[6,11]$. The role of UCMA in calcification processes suggests that UCMA may play an active role in calcium-mediated signaling pathways and mineralization processes [6-8, 10, 12]. Above mentioned studies suggest that UCMA may be an essential regulator in modulating mineralization at systemic and tissue levels. Moreover, there is only one study investigating the association of UCMA with circulating calciprotein particles and extracellular vesicles in vascular calcification in CKD stage 3-5 patients [9]. Also, the molecular mechanism of UCMA action remains unclear in CKD including hemodialysis (HD) patients. Moreover, clarifying the role of UCMA in relation to calcification is crucial for the development of new therapies and biomarkers for CKD patients at risk for cardiovascular disease.

In the current study, we aimed to investigate serum total UCMA levels and its association with MGP, OC, and Fetuin-A. We also evaluated correlations between UCMA and routine calcium metabolism parameters in CKD and HD patients.

\section{MATERIAL AND METHODS}

\section{Subjects}

\section{Study and Control Groups}

Thirty-seven patients with CKD stage 3-5, and 41 prevalent HD patients were enrolled in the study. Inclusion criteria for CKD patients were as follows; age $>18$ years, no acute cardiovascular event, infection or surgical intervention during the previous three months, no pregnancy, and no recent history of malignancy. The control group comprised 34 age- and sex-matched healthy subjects. Patients with a history of CVD and those on vitamin $D$, warfarin therapy, and hormone therapy with parathyroid hormone were excluded from the present study. The stage of CKD was detected by the estimated glomerular filtration rate (eGFR), with respect to the Chronic Kidney Disease Epidemiology Collaboration (CKD-EPI) Equation [13]. The demographic data of all the participants were collected from the HD unit and the hospital information system. The study protocol was approved by the Human Ethics Committee of the Hatay Mustafa Kemal University. Informed written consent was obtained from all the patients and healthy controls. 


\section{Specimen Collection}

Blood was drawn without stasis before the start of the midweek dialysis session in all HD patients. Fasting venous blood samples were collected into vacutainer tubes from patients and healthy subjects and were centrifuged at $1500 \times \mathrm{g}$, for $10 \mathrm{~min}$ within one $\mathrm{h}$ after sampling. After separation, biochemical parameters were measured and serum samples were aliquoted for Enzyme-linked Immunosorbent Assay (ELISA) and stored at $-80^{\circ} \mathrm{C}$ until the time of assay.

\section{Measurement of Biochemical Parameters}

Biochemical parameters were measured using routine laboratory methods. Serum glucose, creatinine, albumin, calcium, phosphorus, and ferritin levels were measured on Siemens ADVIA 1800 Chemistry Analyzer, serum intact PTH (iPTH) levels were measured on Siemens Immulite 2000 XPi Immunassay System. Hemoglobin and hematocrit levels were measured on Mindray BC-6800 Complete Blood Counts Analyzer (Shenzhen, China). The eGFR is calculated by using the CKD-EPI equation.

\section{Measurement of serum UCMA, MGP, OC, and Fetuin-A}

Serum UCMA, Matrix Gla Protein (MGP), Osteocalcin (OC), and Fetuin-A concentrations were analyzed by a commercial ELISA test kit according to the manufacturer's protocol. The intra-assay and inter-assay coefficients of variation and detection range for parameters were shown in Table 1. ELISA parameters were analyzed by Multiskan Go (ThermoScientific) ELISA reader.

\section{Statistical analysis}

We analyzed all data using SPSS statistical package software version 22.0 (Chicago, IL, USA). Categorical and continuous variables were analyzed using ANOVA and chi-square tests, respectively. All data were tested for normality of distribution using the Kolmogorov-Smirnov test. The Mann-Whitney $U$ test or independent-sample t-test was used in the comparison of two groups as appropriate. We used the same tests to compare the means of the examined variables in patients with different characteristics. Pearson correlation test or Spearman correlation test was used to evaluate the correlation between variables as appropriate. $\mathrm{P}<0.05$ value was considered statistically significant. We expressed all data as mean \pm standard deviation or mean \pm standard error of the mean.

Table 1. The intra-assay and inter-assay coefficients of variation and detection range for parameters

\begin{tabular}{lccc}
\hline Parameters & $\begin{array}{c}\text { Intra- } \\
\text { assay }\end{array}$ & $\begin{array}{c}\text { Inter- } \\
\text { assay }\end{array}$ & Detection range \\
\hline UCMA & $<8 \%$ & $<10 \%$ & $0.156-10 \mathrm{ng} / \mathrm{mL}$ \\
MGP & $<10 \%$ & $<12 \%$ & $0.625-40 \mathrm{ng} / \mathrm{mL}$ \\
OC & $<8.3 \%$ & $<8.1 \%$ & $1.2-75 \mathrm{ng} / \mathrm{mL}$ \\
Fetuin-A & $<8 \%$ & $<10 \%$ & $9.38-600 \mathrm{ng} / \mathrm{mL}$
\end{tabular}

UCMA: Upper Zone of Growth Plate and Cartilage Matrix, MGP: Matrix Gla Protein, OC: Osteocalcin.

\section{RESULTS}

\section{Patients and healthy subjects}

The study was performed on 112 adults, including 34 healthy volunteers, 37 patients with CKD stage 3 - 5, and $41 \mathrm{HD}$ patients. Clinical characteristics and laboratory results of the study groups are shown in Table 2. No significant differences existed among the study groups in terms of age, sex, and body mass index. The mean dialysis duration and $\mathrm{Kt} / \mathrm{V}$ values of the $\mathrm{HD}$ patients were $75.82 \pm 61.27$ months, $1.76 \pm .22$, respectively.

\section{Serum total UCMA Concentrations and Vascular calcification-related protein concentrations in CKD and HD patients}

Serum MGP, OC, and Fetuin-A levels were different in CKD and HD patients, as shown in Figure 1. Serum total UCMA levels were markedly and significantly increased in the CKD and HD patients as compared 
to those in the healthy controls $(2.23 \pm .27 \mathrm{ng} / \mathrm{mL}, 2.54 \pm .29 \mathrm{ng} / \mathrm{mL}$, vs. .96 $\pm .17 \mathrm{ng} / \mathrm{mL}$, respectively, $\mathrm{p}<0.0001)$. However, there was no significant difference between UCMA levels of CKD and HD patients ( $p>0.05)$. Similarly, the serum MGP concentrations were significantly higher in the CKD and HD patients as compared to those in the controls $(202.35 \pm 7.77 \mathrm{ng} / \mathrm{mL}, 224 \pm 7.11 \mathrm{ng} / \mathrm{mL}$ vs. $116.79 \pm 4.21 \mathrm{ng} / \mathrm{mL}$, respectively, $\mathrm{p}<0.0001)$. Also, we observed a significant difference in the serum levels of MGP between the CKD and HD patients $(p<0.05)$.

Serum OC levels in CKD and HD patients were found to be significantly higher than those in the control group $(18.29 \pm 1.9 \mathrm{ng} / \mathrm{mL}, 92.06 \pm 16.87 \mathrm{ng} / \mathrm{mL}$, vs. $3.29 \pm 20 \mathrm{ng} / \mathrm{mL}$, respectively, $\mathrm{p}<0.0001)$. In contrast, a marked decrease of serum Fetuin-A levels was observed in HD patients as compared to that in the controls $(30.35 \pm 3.86$ vs. $86.62 \pm 14.38, p<0.0001)$.

Table 2. Clinical characteristics and serum biochemistry of healthy subjects and CKD patients

\begin{tabular}{|c|c|c|c|c|}
\hline & $\begin{array}{c}\text { Healthy } \\
\text { subjects } \\
(n=34)\end{array}$ & $\begin{array}{l}\text { CKD stage } 3-5 \\
\text { patients }(n=37)\end{array}$ & $\begin{array}{l}\text { Hemodialysis } \\
\text { patients }(n=41)\end{array}$ & $p$ value \\
\hline Age (Years) & $51.17 \pm 8.9$ & $55 \pm 13.04$ & $56.65 \pm 8.77$ & $P>0.05$ \\
\hline Sex, Male/Female & $17 / 17$ & $16 / 21$ & $26 / 15$ & $P>0.05$ \\
\hline Body mass index $\left(\mathrm{kg} / \mathrm{m}^{2}\right)$ & $28.69 \pm 3.75$ & $28.39 \pm 5.22$ & $26.12 \pm 5.43$ & $P>0.05$ \\
\hline eGFR $\left(\mathrm{mL} / \mathrm{min} / 1.73 \mathrm{~m}^{2}\right)$ & $102.89 \pm 11.38$ & $25.78 \pm 11.27$ & - & $P<0.001^{a}$ \\
\hline Underlying Kidney disease & - & & & \\
\hline Chronic glomerulonephritis & & 4 & & \\
\hline Diabetes & & 16 & 24 & \\
\hline Hypertensive nephropathy & & 9 & 5 & \\
\hline Polycystic kidney disease & & 2 & 1 & \\
\hline Unknown & & 6 & 11 & \\
\hline Hemoglobin (g/dL) & $13.85 \pm 1.5$ & $11.05 \pm 1.9$ & $11.09 \pm 1.12$ & $\begin{array}{l}P<0.001^{a, b} \\
P>0.05^{c}\end{array}$ \\
\hline Hematocrit (\%) & $42.19 \pm 3.92$ & $34.56 \pm 5.90$ & $33.98 \pm 3.50$ & $\begin{array}{l}P<0.001^{a, b} \\
P>0.05^{c}\end{array}$ \\
\hline Albumin (g/dL) & $4.47 \pm .20$ & $4.00 \pm .53$ & $3.94 \pm .30$ & $\begin{array}{l}P<0.001^{a, b} \\
P>0.05^{c}\end{array}$ \\
\hline Ferritin $(\mathbf{n g} / \mathbf{m L})$ & $78.91 \pm 71.14$ & $179.58 \pm 199.05$ & $801.06 \pm 580.42$ & $\begin{array}{l}P>0.05^{a} \\
P<0.001^{b, c}\end{array}$ \\
\hline Calcium (mg/dL) & $9.53 \pm .29$ & $9.09 \pm .63$ & $8.7 \pm .63$ & $P<0.005^{a, b, c}$ \\
\hline Phosphorus (mg/dL) & $3.21 \pm .41$ & $4.24 \pm 1.26$ & $5.06 \pm 1.17$ & $\begin{array}{l}P<0.001^{a, b} \\
P<0.003^{c}\end{array}$ \\
\hline $\begin{array}{l}\text { Calcium-Phosphorus product } \\
\mathrm{mg}^{2} / \mathrm{dl}^{2}\end{array}$ & $30.73 \pm 4.4$ & $39.53 \pm 9.23$ & $44.32 \pm 11.88$ & $\begin{array}{l}P<0.002^{a, b} \\
P=0.068^{c}\end{array}$ \\
\hline $\begin{array}{l}\text { Intact Parathyroid hormone } \\
(\mathrm{pg} / \mathrm{mL})\end{array}$ & $65.40 \pm 27.41$ & $184.9 \pm 154.73$ & $654.37 \pm 388.59$ & $\begin{array}{l}P>0.05^{a} \\
P<0.001^{b, c}\end{array}$ \\
\hline Glucose $(\mathrm{mg} / \mathrm{dL})$ & $90.15 \pm 1.8$ & $103.80 \pm 28.03$ & $142.95 \pm 105.95$ & $\begin{array}{l}P>0.05^{a} \\
P<0.05^{b, c}\end{array}$ \\
\hline
\end{tabular}

The data were expressed as mean $\pm S D$. aComparison between Healthy subjects and CKD patients. ${ }^{b}$ Comparison between Healthly subjects and HD patients. ${ }^{\circ}$ Comparison between CKD and HD patients. UCMA: Upper Zone of Growth Plate and Cartilage Matrix, MGP: Matrix Gla Protein, OC: Osteocalcin. 
a)

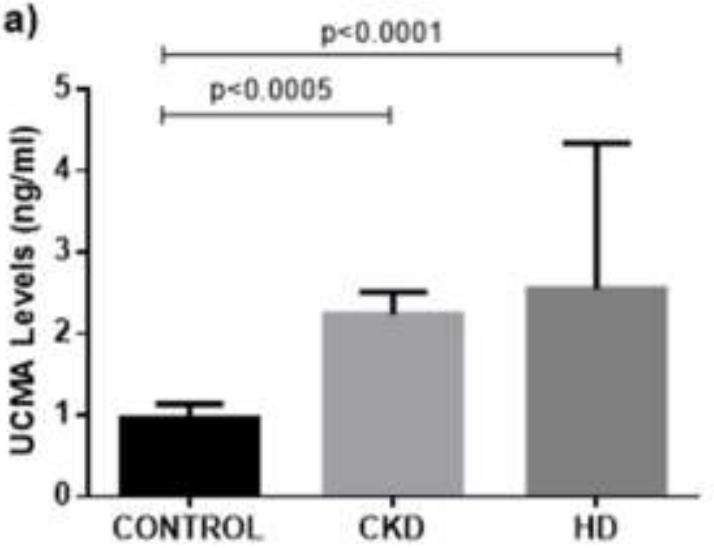

c)

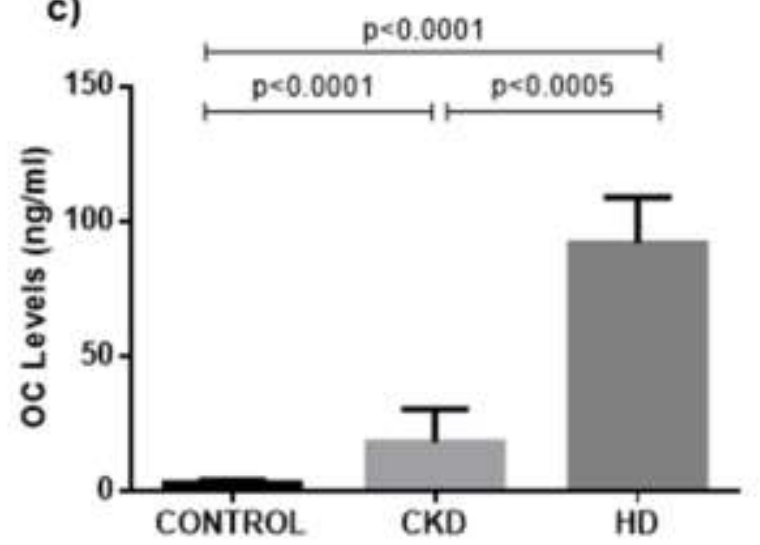

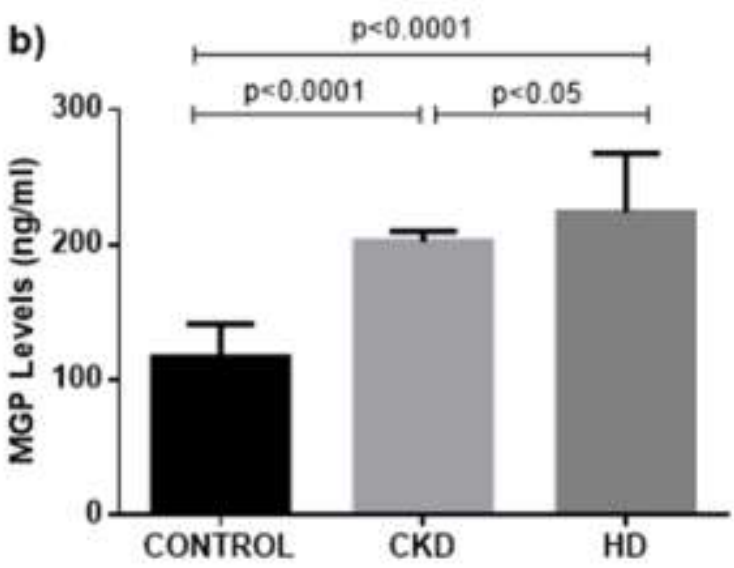

d)

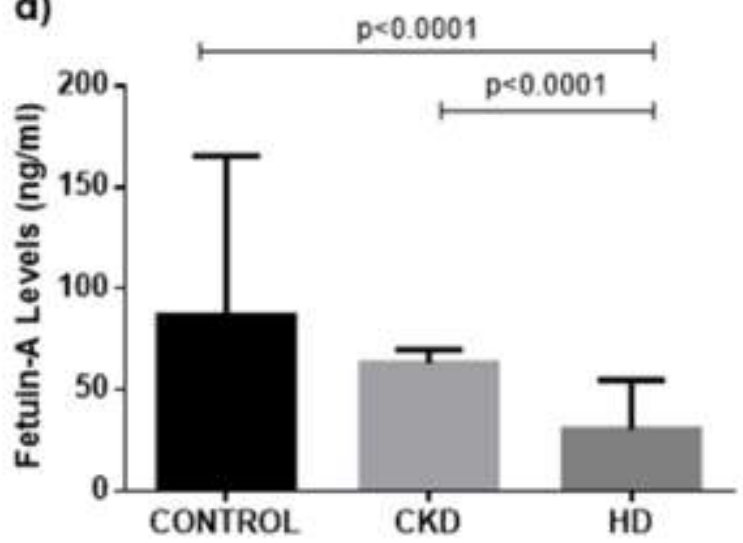

Figure 1. Serum protein levels of UCMA (a), MGP (b), OC (c), and Fetuin-A (d) in healthy controls, CKD patients and HD patients. Sera were collected from healthy controls $(n=34)$, patients with $C K D(n=37)$ and patients with $H D(n=41)$. The protein levels were measured with ELISA. Each sample was assayed in duplicate. Data were presented mean \pm SEM.

\section{Correlation of serum UCMA concentrations with eGFR and biochemical parameters}

We detected a significant relationship between serum UCMA levels and some biochemical parameters in the overall study population. eGFR is an indicator of kidney function level and the stage of kidney disease [14]. Furthermore, serum PTH concentrations have a relationship with cardiovascular morbidity in patients with CKD [15]. We performed a correlation analysis to determine the relationship between serum UCMA levels and renal function and calcification. As shown in Table 3, serum total UCMA levels showed negative correlations with hemoglobin, calcium, and eGFR, while showed positive relationships with iPTH. However, no significant association was observed between serum UCMA levels and serum phosphorus, calcium $x$ phosphorus product. There was no correlation of UCMA concentrations with dialysis duration and $\mathrm{Kt} / \mathrm{V}$ in patients with HD. Similarly, serum MGP concentrations were significantly negatively correlated with hemoglobin, calcium, Fetuin-A, and eGFR, but positively correlated with UCMA, OC, calcium - phosphorus product, phosphorus, and IPTH. Furthermore, serum OC levels showed a significant and negative correlation with hemoglobin, calcium, Fetuin-A, and eGFR, while showed a positive correlation with ferritin, phosphorus, calcium - phosphorus product, iPTH, and MGP. Serum Fetuin-A levels were significantly negatively correlated with ferritin, iPTH, MGP, and OC, but were positively correlated with hemoglobin and calcium. 
Table 3. Correlations between serum protein levels and various clinical and serum biochemistry parameters

\begin{tabular}{|c|c|c|c|c|}
\hline Parameters & UCMA & MGP & OC & Fetuin-A \\
\hline \multirow[t]{2}{*}{ Age (Years) } & $r=0.253$ & NS & $r=0.262$ & NS \\
\hline & $P<0.05$ & & $P<0.01$ & \\
\hline \multirow[t]{2}{*}{ Body mass index $\left(\mathrm{kg} / \mathrm{m}^{2}\right)$} & NS & $r=-0.231$ & $r=-0.343$ & $r=0.273$ \\
\hline & & $P<0.05$ & $P<0.005$ & $P<0.05$ \\
\hline \multirow[t]{2}{*}{ eGFR } & $r=-0.349$ & $r=-0.674$ & $r=-0.721$ & NS \\
\hline & $P<0.01$ & $P<0.001$ & $P<0.001$ & \\
\hline Dialysis duration (Month) & NS & NS & NS & NS \\
\hline \multirow[t]{2}{*}{ Hemoglobin $(g / d L)$} & $r=-0.281$ & $r=-0.506$ & $r=-0.508$ & $r=0.231$ \\
\hline & $P<0.005$ & $P<0.001$ & $P<0.001$ & $P<0.05$ \\
\hline \multirow[t]{2}{*}{ Ferritin (ng/mL) } & $r=0.316$ & $r=0.439$ & $r=0.569$ & $r=-0.315$ \\
\hline & $P<0.005$ & $P<0.001$ & $P<0.001$ & $P<0.05$ \\
\hline \multirow[t]{2}{*}{ Calcium (mg/dL) } & $r=-0.336$ & $r=-0.306$ & $r=-0.465$ & $r=0.421$ \\
\hline & $P<0.001$ & $P<0.005$ & $P<0.001$ & $P<0.001$ \\
\hline \multirow[t]{2}{*}{ Phosphorus (mg/dL) } & $r=0.252$ & $r=0.545$ & $r=0.580$ & $r=-0.286$ \\
\hline & $P<0.01$ & $P<0.001$ & $P<0.001$ & $P<0.005$ \\
\hline \multirow{2}{*}{$\begin{array}{l}\text { Calcium-Phosphorus product } \\
\mathrm{mg} 2 / \mathrm{dl} 2\end{array}$} & NS & $r=0.506$ & $r=0.476$ & NS \\
\hline & & $P<0.001$ & $P<0.001$ & \\
\hline \multirow{2}{*}{$\begin{array}{l}\text { Intact Parathyroid hormone } \\
(\mathrm{pg} / \mathrm{mL})\end{array}$} & $r=0.360$ & $r=0.625$ & $r=0.798$ & $r=-0.386$ \\
\hline & $P<0.001$ & $P<0.001$ & $P<0.001$ & $P<0.001$ \\
\hline \multirow{3}{*}{$\begin{array}{l}\mathrm{Kt} / \mathrm{V} \\
\mathrm{UCMA}\end{array}$} & NS & NS & NS & NS \\
\hline & & $r=0.350$ & $r=0.353$ & NS \\
\hline & & $P<0.001$ & $P<0.001$ & \\
\hline \multirow[t]{2}{*}{ MGP } & $r=0.350$ & & $r=0.772$ & $r=-0.223$ \\
\hline & $P<0.001$ & & $P<0.001$ & $P<0.05$ \\
\hline \multirow[t]{2}{*}{ OC } & $r=0.353$ & $r=0.772$ & & $r=-0.384$ \\
\hline & $P<0.001$ & $P<0.001$ & & $P<0.001$ \\
\hline \multirow[t]{2}{*}{ Fetuin-A } & NS & $r=-0.223$ & $r=-0.384$ & \\
\hline & & $P<0.05$ & $P<0.001$ & \\
\hline
\end{tabular}

NS: Not significant, UCMA: Upper Zone of Growth Plate and Cartilage Matrix, MGP: Matrix Gla Protein, OC: Osteocalcin.

\section{DISCUSSION}

Decreased kidney function is linked to poor clinical outcomes, with clinical manifestations in a wide variety of other organ systems, including endocrine, musculoskeletal, and hematologic. CKD is also associated with a much higher risk of CVD. This is partially due to vascular calcifications and accelerated atherosclerosis, as a result of abnormal calcium phosphate regulation in patients with CKD [4]. Although secondary hyperparathyroidism due to decreased $\mathrm{Ca}$ levels in plasma plays a vital role at the beginning of the disturbed Ca-P homeostasis, the underlying mechanism is not fully understood in CKD. Moreover, the identification of non-invasive biomarkers predicting CKD progression will contribute to the development of therapeutic strategies for CKD [16].

Recently, several VKDPs have been shown to play a significant role in the calcium mineral balance and have a linkage to the dynamics of vascular complications in CKD patients. UCMA, as a novel member of VKDP, is expressed in the human vascular system and plays an essential role in the calcification process in different clinical conditions including CVD and osteoarthritis [7,10]. In the current study, we evaluated both CKD and HD patients. We, for the first time, showed that total UCMA levels were significantly increased in these subjects compared to healthy controls.

UCMA is synthesized by Vascular Smooth Muscle Cells (VSCMs) in vascular tissues and directly interacts with calcium crystals inhibiting their growth and maturation through its calcium-binding Gla residues $[9,12]$. Similar to other VKDP, its activity is well known to depend on its $Y$-carboxylation status in the presence of adequate vitamin $\mathrm{K}$. The gamma carboxylation is required for the physiological function of vitamin $\mathrm{K}$ dependent proteins including UCMA. Un/undercarboxylated forms of these proteins are generally considered to have low or non-functional activity [17-20]. It has been shown that decreased $y$-carboxylation of VKDP induce VC due to inadequate vitamin K intake and genetic defects in the $\mathrm{Y}$-carboxylase enzyme [21-23]. Moreover, vitamin $\mathrm{K}$ deficiency has been reported in most patients with CKD and HD [24]. In our study, we 
analyzed only the serum total UCMA levels but not CUCMA in patients with CKD and HD. We also measured serum MGP levels in the same study group and found increased levels in CKD patients, including HD compared to the healthy control group. MGP belongs to the same family of VKDP, similar to UCMA, and one of the potent inhibitors of VC [25].

There is also a weak but significant correlation between these two proteins $(r=0.350, p<0.001)$. There are conflicting data in the literature regarding the role of MGP in CKD patients. Hallajzadeh and coauthors showed that MGP levels were significantly decreased in dialysis patients compared to the control group [26]. On the other hand, Gluba-Brzózka and coauthors showed that there is no significant difference in the MGP concentrations between the healthy control group and all stages of CKD [27]. In this study, we showed that MGP levels were positively correlated with UCMA and OC, but negatively correlated with Fetuin-A. These positive correlations were expected results because both MGP, UCMA and OC are VKDP. In accordance with previous studies, we found that OC levels were increased in CKD and HD groups compared to the healthy control group [28].

In a previous study, Kurnatowska and coauthors showed that un-MGP levels were higher in patients at stage 5 CKD and significantly decreased by vitamin K2 supplementation. They have attributed these high un-MGP levels to low vitamin K levels in patients with CKD [29]. Because uncarboxylated forms of several VKDPs levels in plasma reflects indirectly vitamin $\mathrm{K}$ status of patients [30]. As a consequence, we may speculate that increased UCMA levels in our study group might be associated with decreased $y$-carboxylation due to inadequate vitamin $\mathrm{K}$ levels in patients with CKD. Because, low concentrations of vitamin $\mathrm{K}$ in CKD patients have been well known condition and resulted from dietary restrictions and the use of phosphate binders that can also bind vitamin $\mathrm{K}$ [31-33]. It has been also reported that UCMA in rats and human is expressed and accumulated in the skin and in the vascular system in another study [10]. Therefore, decreased carboxylation and lack of activity can also lead to high demand and up-regulation of UCMA synthesis and increased total UCMA levels in plasma. Serum UCMA levels were also negatively correlated with eGFR values and positively correlated with serum PTH, OC and phosphorus levels (Table 3). These weak but statistically significant correlations between commonly known VC risk factors like decreased eGFR and increased PTH and OC support the possible role of UCMA in the pathogenesis of VC in CKD.

As a consequence, reduced levels of cUCMA as a mineralization inhibitor may contribute to the development of VC in CKD and HD patients. In human serum, various forms of UCMA (carboxylated / uncarboxylated UCMA) may show different levels of expression, indicating that various forms of UCMA have different roles in the mineralization process. This may be closely related to the amount of vitamin $\mathrm{K}$ in the blood [10]. On the other hand, Viegas and coauthors, reported that extracellular vesicles (EVs) secreted from VSMCs included UCMA as well as MGP, Fetuin A. It was also shown in their study that, these EVs contain higher amounts of calcium and lower UCMA/GRP and MGP levels under calcification conditions. [7]. A recent study investigating the association of UCMA with calciprotein particles (CPPs) and EVs in patients with CKD showed that UCMA is a component of serum CPPs and EVs. The results of this study indicated that CPPs and EVs play an important role in the development of VC in CKD, and serum CPPs and EVs contain low levels of UCMA and Fetuin-A. These results are remarkable for the major role of cUCMA as an inhibitory factor to prevent calcification [9]. Taking into account observations from other studies, our results suggest that UCMA may be a novel, promising marker of CVD risk in CKD patients.

Fetuin-A, a circulating protein, is predominantly formed by liver cells and is a potent inhibitor of calcification [34]. Oikawa And coauthors found that serum Fetuin-A levels of HD patients decreased as compared to healthy controls [35]. The low Fetuin-A levels are associated with increased mortality [36, 37]. We founded that serum Fetuin A levels were significantly reduced in HD patients compared with the healthy control group, which was consistent with the results of previous studies [35, 36]. However, we could not find an association between serum UCMA and Fetuin-A levels in study groups.

Notwithstanding these contributions, our study has some limitations. First, since this study is crosssectional, our results should be interpreted carefully. Second, we evaluated only serum total UCMA levels, not carboxylated UCMA form and unUCMA separately. Our findings should be verified with further studies with larger samples and different forms of UCMA.

\section{CONCLUSION}

Increased total UCMA levels may have a role in the Ca metabolism disorder and could be related to the pathogenesis of VC in patients with CKD. A better understanding of the molecular mechanisms involved in Ca metabolism and the identification of new active players such as UCMA are critical for the development of therapeutic strategies in CKD. Large-scale studies that examine circulating levels of all forms of UCMA will 
enable us to consider the potential use of UCMA as a new biomarker in the pathogenesis of VC among patients with CKD.

Funding: This work is supported by the Scientific Research Project Fund of Hatay Mustafa Kemal University under project number 18.M.063.

Conflicts of Interest: All authors declare that there is no conflict of interest. The funders had no role in the design of the study; in the collection, analyses, or interpretation of data; in the writing of the manuscript, or in the decision to publish the results.

Author Contributions: H.M.O., O.Ö., and F.H.T. conceived and designed the study. H.M.O., F.H.T., O.Ö., S.D., and A.A. wrote/drafted/edited the manuscript and interpreted the results. H.M.O., S.D., F.H.T., and A.A. performed laboratory analysis and collected sample. H.M.O., O.Ö, S.D., and F.H.T. conducted statistical analyses, prepared graphs/figures and revised the manuscript. All authors read and approved the final version of this manuscript.

\section{REFERENCES}

1. Stevens PE, Levin A. Kidney Disease: Improving Global Outcomes Chronic Kidney Disease Guideline Development Work Group, Members, Evaluation and management of chronic kidney disease: synopsis of the kidney disease: improving global outcomes 2012 clinical practice guideline. Ann Intern Med, 2013;158(11):825-30.

2. Luyckx VA, Tonelli M, Stanifer JW. The global burden of kidney disease and the sustainable development goals. Bull World Health Organ, 2018;96(6):414-422D.

3. Viegas C, Araujo N, Marreiros C, Simes D. The interplay between mineral metabolism, vascular calcification and inflammation in Chronic Kidney Disease (CKD): challenging old concepts with new facts. Aging (Albany NY), 2019;11(12):4274-4299.

4. Mejia N, Roman-Garcia P, Miar AB, Tavira B, Cannata-Andia JB. Chronic kidney disease--mineral and bone disorder: a complex scenario. Nefrologia, 2011;31(5):514-9.

5. Hill Gallant KM, Spiegel DM. Calcium Balance in Chronic Kidney Disease. Curr Osteoporos Rep, 2017;15(3):214221.

6. Viegas CS, Simes DC, Laize V, Williamson MK, Price PA, Cancela ML. Gla-rich protein (GRP), a new vitamin Kdependent protein identified from sturgeon cartilage and highly conserved in vertebrates. J Biol Chem, 2008;283(52):36655-64.

7. Viegas CS, Rafael MS, Enriquez JL, Teixeira A, Vitorino R, Luis IM, et al. Gla-rich protein acts as a calcification inhibitor in the human cardiovascular system. Arterioscler Thromb Vasc Biol, 2015;35(2):399-408.

8. Viegas CSB, Costa RM, Santos L, Videira PA, Silva Z, Araujo N, et al. Gla-rich protein function as an antiinflammatory agent in monocytes/macrophages: Implications for calcification-related chronic inflammatory diseases. PLoS One, 2017;12(5):e0177829.

9. Viegas CSB, Santos L, Macedo AL, Matos AA, Silva AP, Neves PL, et al. Chronic Kidney Disease Circulating Calciprotein Particles and Extracellular Vesicles Promote Vascular Calcification: A Role for GRP (Gla-Rich Protein). Arterioscler Thromb Vasc Biol, 2018;38(3):575-587.

10.Viegas CS, Cavaco S, Neves PL, Ferreira A, Joao A, Williamson MK, et al. Gla-rich protein is a novel vitamin Kdependent protein present in serum that accumulates at sites of pathological calcifications. Am J Pathol, 2009;175(6):2288-98.

11. Cancela ML, Conceicao N, Laize V. Gla-rich protein, a new player in tissue calcification? Adv Nutr, 2012;3(2):17481.

12. Viegas CS, Herfs M, Rafael MS, Enriquez JL, Teixeira A, Luis IM, et al. Gla-rich protein is a potential new vitamin $\mathrm{K}$ target in cancer: evidences for a direct GRP-mineral interaction. Biomed Res Int, 2014; 2014: 340216.

13.Levey AS, Stevens LA, Schmid CH, Zhang YL, Castro AF, 3rd, Feldman HI, et al. A new equation to estimate glomerular filtration rate. Ann Intern Med, 2009;150(9):604-12.

14.Mula-Abed WA, Al Rasadi K, Al-Riyami D. Estimated Glomerular Filtration Rate (eGFR): A Serum Creatinine-Based Test for the Detection of Chronic Kidney Disease and its Impact on Clinical Practice. Oman Med J, 2012;27(2):10813.

15.Pontoriero G, Cozzolino M, Locatelli F, Brancaccio D. CKD patients: the dilemma of serum PTH levels. Nephron Clin Pract, 2010;116(4):c263-8.

16. Sarnak MJ, Foley RN. Cardiovascular mortality in the general population versus dialysis: a glass half full or empty? Am J Kidney Dis, 2011;58(1):4-6.

17.Cranenburg EC, Schurgers LJ, Vermeer C. Vitamin K: the coagulation vitamin that became omnipotent. Thromb Haemost, 2007;98(1):120-5.

18.Schurgers LJ, Teunissen KJ, Knapen MH, Kwaijtaal M, van Diest R, Appels A, et al. Novel conformation-specific antibodies against matrix gamma-carboxyglutamic acid (Gla) protein: undercarboxylated matrix Gla protein as marker for vascular calcification. Arterioscler Thromb Vasc Biol, 2005;25(8):1629-33.

19.McCann JC, Ames BN. Vitamin K, an example of triage theory: is micronutrient inadequacy linked to diseases of aging? Am J Clin Nutr, 2009;90(4):889-907. 
20.Schurgers LJ, Spronk HM, Skepper JN, Hackeng TM, Shanahan CM, Vermeer C, et al. Post-translational modifications regulate matrix Gla protein function: importance for inhibition of vascular smooth muscle cell calcification. J Thromb Haemost, 2007;5(12):2503-11.

21. Willems BA, Vermeer C, Reutelingsperger CP, Schurgers LJ. The realm of vitamin K dependent proteins: shifting from coagulation toward calcification. Mol Nutr Food Res, 2014;58(8):1620-35.

22.Kruger T, Oelenberg S, Kaesler N, Schurgers LJ, van de Sandt AM, Boor P, et al. Warfarin induces cardiovascular damage in mice. Arterioscler Thromb Vasc Biol, 2013;33(11):2618-24.

23.Schurgers LJ, Spronk HM, Soute BA, Schiffers PM, DeMey JG, Vermeer C. Regression of warfarin-induced medial elastocalcinosis by high intake of vitamin $\mathrm{K}$ in rats. Blood, 2007;109(7):2823-31.

24.McCabe KM, Adams MA, Holden RM. Vitamin K status in chronic kidney disease. Nutrients, 2013; 5(11): 4390-8.

25.Dalmeijer GW, van der Schouw YT, Vermeer C, Magdeleyns EJ, Schurgers LJ, Beulens JW. Circulating matrix Gla protein is associated with coronary artery calcification and vitamin $\mathrm{K}$ status in healthy women. $\mathrm{J}$ Nutr Biochem, 2013;24(4):624-8.

26. Hallajzadeh J, Ghorbanihaghjo A, Argani H, Dastmalchi S, Rashtchizadeh N. Growth Arrest-specific 6 Protein and Matrix Gla Protein in Hemodialysis Patients. Iran J Kidney Dis, 2015;9(3):249-55.

27.Gluba-Brzozka A, Michalska-Kasiczak M, Franczyk-Skora B, Nocun M, Banach M, Rysz J. Markers of increased cardiovascular risk in patients with chronic kidney disease. Lipids Health Dis, 2014;13:135.

28. Marchelek-Mysliwiec M, Wisniewska M, Nowosiad-Magda M, Safranow K, Kwiatkowska E, Banach B, et al. Association Between Plasma Concentration of Klotho Protein, Osteocalcin, Leptin, Adiponectin, and Bone Mineral Density in Patients with Chronic Kidney Disease. Horm Metab Res, 2018;50(11):816-821.

29.Kurnatowska I, Grzelak P, Masajtis-Zagajewska A, Kaczmarska M, Stefanczyk L, Vermeer C, et al. Plasma Desphospho-Uncarboxylated Matrix Gla Protein as a Marker of Kidney Damage and Cardiovascular Risk in Advanced Stage of Chronic Kidney Disease. Kidney Blood Press Res, 2016;41(3):231-9.

30. Shea MK, Holden RM. Vitamin K status and vascular calcification: evidence from observational and clinical studies. Adv Nutr, 2012;3(2):158-65.

31. Cozzolino M, Mangano M, Galassi A, Ciceri P, Messa P, Nigwekar S. Vitamin K in Chronic Kidney Disease. Nutrients, $2019 ; 11(1)$.

32. McCabe KM, Booth SL, Fu X, Shobeiri N, Pang JJ, Adams MA, et al. Dietary vitamin K and therapeutic warfarin alter the susceptibility to vascular calcification in experimental chronic kidney disease. Kidney Int, 2013; 83(5): 835-44.

33.Neradova A, Schumacher SP, Hubeek I, Lux P, Schurgers LJ, Vervloet MG. Phosphate binders affect vitamin K concentration by undesired binding, an in vitro study. BMC Nephrol, 2017;18(1):149.

34. Ketteler M, Vermeer C, Wanner C, Westenfeld R, Jahnen-Dechent W, Floege J. Novel insights into uremic vascular calcification: role of matrix Gla protein and alpha-2-Heremans Schmid glycoprotein/fetuin. Blood Purif, 2002;20(5):473-6.

35. Oikawa O, Higuchi T, Yamazaki T, Yamamoto C, Fukuda N, Matsumoto K. Evaluation of serum fetuin-A relationships with biochemical parameters in patients on hemodialysis. Clin Exp Nephrol, 2007;11(4):304-308.

36. Stenvinkel P, Wang K, Qureshi AR, Axelsson J, Pecoits-Filho R, Gao P, et al. Low fetuin-A levels are associated with cardiovascular death: Impact of variations in the gene encoding fetuin. Kidney Int, 2005;67(6):2383-92.

37. Ketteler M, Wanner C, Metzger T, Bongartz P, Westenfeld R, Gladziwa U, et al. Deficiencies of calcium-regulatory proteins in dialysis patients: a novel concept of cardiovascular calcification in uremia. Kidney Int Suppl, 2003(84):S84-7.

(C) 2020 by the authors. Submitted for possible open access publication under the terms and conditions of the Creative Commons Attribution (CC BY NC) license (https://creativecommons.org/licenses/by-nc/4.0/). 


\section{ERRATUM}

In the Article "Upper Zone of Growth Plate and Cartilage Matrix Associated (UCMA) Levels in Patients with Chronic Kidney Disease" with Running title: "UCMA can play a crucial role in calcium regulation", DOI number: http://dx.doi.org/10.1590/1678-4324-2020190594, published in the journal Brazilian Archives of Biology and Technology, vol. 63, pages 1-6.

That read:

“...Upper Zone of Growth Plate and Cartilage Matrix (UCMA..."

Read:

“...Upper Zone of Growth Plate and Cartilage Matrix Associated (UCMA) ...” 